\title{
Community Health Nursing
}

National Cancer Institute

\section{Source}

National Cancer Institute. Community Health Nursing. NCI Thesaurus. Code C16456.

A discipline in nursing with a focus on the delivery of health care and disease prevention to residents living in a common geographic area. 